\title{
Detection and quantification of glycosylated queuosine modified tRNAs by acid denaturing and APB gels
}

\author{
WEN ZHANG, ${ }^{1}$ RUYI XU, ${ }^{2,3}$ ŻANETA MATUSZEK ${ }^{4}{ }^{2} \mathrm{ZHEN} \mathrm{CAI}^{2,3}$ and TAO PAN ${ }^{4}$ \\ ${ }^{1}$ Department of Chemistry, University of Chicago, Chicago, Illinois 60637, USA \\ ${ }^{2}$ Bone Marrow Transplantation Center, The First Affiliated Hospital, School of Medicine, Zhejiang University, Hangzhou, 310006, China \\ ${ }^{3}$ Institute of Hematology, Zhejiang University, Zhejiang, 310006, China \\ ${ }^{4}$ Department of Biochemistry and Molecular Biology, University of Chicago, Chicago, Illinois 60637, USA
}

\begin{abstract}
Queuosine (Q) is a conserved tRNA modification in bacteria and eukaryotes. Eukaryotic Q-tRNA modification occurs through replacing the guanine base with the scavenged metabolite queuine at the wobble position of tRNAs with $\mathrm{G}_{34} \mathrm{U}_{35} \mathrm{~N}_{36}$ anticodon (Tyr, His, Asn, Asp) by the QTRT1/QTRT2 heterodimeric enzyme encoded in the genome. In humans, Q-modification in tRNA ${ }^{T y r}$ and tRNA ${ }^{A s p}$ are further glycosylated with galactose and mannose, respectively. Although galactosyl-Q (galQ) and mannosyl-Q (manQ) can be measured by LC/MS approaches, the difficulty of detecting and quantifying these modifications with low sample inputs has hindered their biological investigations. Here we describe a simple acid denaturing gel and nonradioactive northern blot method to detect and quantify the fraction of galQ/manQ-modified tRNA using just microgram amounts of total RNA. Our method relies on the secondary amine group of galQ/man $\mathrm{Q}$ becoming positively charged to slow their migration in acid denaturing gels commonly used for tRNA charging studies. We apply this method to determine the $\mathrm{Q}$ and galQ/manQ modification kinetics in three human cells lines. For $\mathrm{Q}-\mathrm{modification}$, tRNA $^{\text {Asp }}$ is modified the fastest, followed by tRNA ${ }^{\text {His }}$, tRNA ${ }^{\text {Tyr }}$, and tRNA ${ }^{\text {Asn }}$. Compared to Q-modification, glycosylation occurs at a much slower rate for tRNA ${ }^{A s p}$, but at a similar rate for tRNA ${ }^{\text {Tyr }}$. Our method enables easy access to study the function of these enigmatic tRNA modifications.
\end{abstract}

Keywords: queuosine; mannosyl-queuosine; galactosyl-queuosine; acid denaturing PAGE

\section{INTRODUCTION}

tRNA is the most extensively modified RNA in cells. On average, a eukaryotic tRNA contains $\sim 13$ modifications (Machnicka et al. 2013); among these, queuosine (Q) stands out as it is the only known eukaryotic tRNA modification that requires a metabolite from bacteria. First discovered in the 1960s, Q-modification occurs in tRNA families of amino acids Tyr, His, Asn, Asp. These tRNAs have $\mathrm{G}_{34} \mathrm{U}_{35} \mathrm{~N}_{36}$ anticodons, and $\mathrm{G}_{34}$-to- $\mathrm{Q}$ modification occurs exclusively at the wobble anticodon position. tRNA Q-modification in bacteria is synthesized de novo through a biogenesis pathway containing eight steps. Eukaryotes cannot synthesize $\mathrm{Q}$, rather, they depend on scavenging the metabolite queuine from diets or gut microbiome catabolism (Reyniers et al. 1981), followed by the $\mathrm{G}_{34}$-to- $\mathrm{Q}$ incorporation in the same four tRNA families by a multimeric enzyme encoded in the genome (e.g., QTRT1 and QTRT2 genes in humans).

Corresponding author: taopan@uchicago.edu

Article is online at http://www.rnajournal.org/cgi/doi/10.1261/rna. 075556.120.
The exploration of molecular functions of Q-modification has been ongoing since its identification (Vinayak and Pathak 2009; Fergus et al. 2015; Ehrenhofer-Murray 2017). Its occurrence at the wobble anticodon position indicates that it plays a role in mRNA decoding. All Qmodified tRNAs read codons composed of NAC/NAU, so $\mathrm{Q}_{34}$ directly pairs with $\mathrm{C}$ or $\mathrm{U}$ in the third codon position. Indeed, tRNA Q-modification has been shown to affect differential decoding of $\mathrm{C}$ or $\mathrm{U}$ ending codons to influence translation efficiency or protein misfolding (Meier et al. 1985; Tuorto et al. 2018; Müller et al. 2019). tRNA Q-modification may also affect translation fidelity to facilitate genome-wide reprogramming of codon usage in Drosophilids (Zaborske et al. 2014). tRNA Q-modification can also improve the activity of the antioxidant enzymes and suppress oxidative stress (Pathak et al. 2008). In S. pombe, tRNA ${ }^{\text {Asp }} \mathrm{Q}$-modification affects its 5-methyl-C

C 2020 Zhang et al. This article is distributed exclusively by the RNA Society for the first 12 months after the full-issue publication date (see http://rnajournal.cshlp.org/site/misc/terms.xhtml). After 12 months, it is available under a Creative Commons License (Attribution-NonCommercial 4.0 International), as described at http:// creativecommons.org/licenses/by-nc/4.0/. 
modification in the anticodon loop, resulting in differential activity of tRNA ${ }^{\text {Asp }}$ in translation speed, accuracy, and aminoacylation (Bednarova et al. 2017; Tuorto et al. 2018). In human cells, tRNA Q-modification can protect cognate tRNA from ribonuclease cleavage and affects cellular tRNA fragment pools (Wang et al. 2018).

Intriguingly, Q-modified tRNA ${ }^{T y r}$ and tRNA ${ }^{\text {Asp }}$ in many eukaryotes are further glycosylated with galactose and mannose to generate galactosyl-O (galO) and mannosylQ (manQ) (Fig. 1A; Kasai et al. 1975, 1976). To our knowledge, these are the only known tRNA modifications that contain glycoslyation, yet, the function of these glycosylations has remained elusive.

tRNA Q-modification is commonly measured using liquid chromatography/mass spectrometry (LC/MS) or a $\mathrm{N}$-acryloyl-3-aminophenylboronic acid (APB) gel-based approach (Igloi and Kossel 1985; Costa et al. 2004; Zaborske et al. 2014; Pan 2018). Although the LC/MSbased method is powerful and can quantify $\mathrm{Q}$, galactosyl-Q, and mannosyl-Q modified tRNAs (Costa et al. 2004), it requires very large amounts of input RNA, making its application difficult for routine investigation on these tRNA modifications. The glycosylated tRNA ${ }^{\text {Tyr }}$ and tRNA ${ }^{\text {Asp }}$ can be isolated by lectin-Sepharose affinity chro-
A

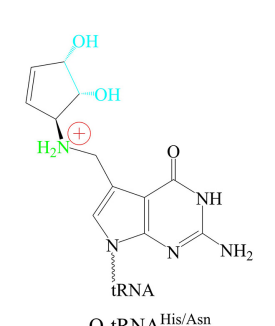

Q-tRNA ${ }^{\text {His/Asn }}$

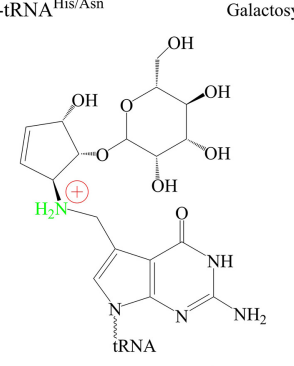

Mannosyl-tRNA Asp
B

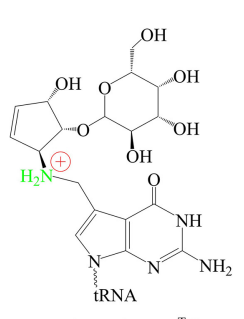

Galactosyl-tRNA $^{\text {Tyr }}$
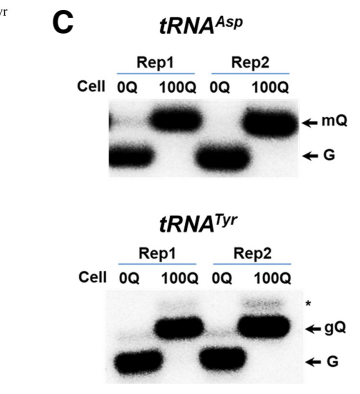

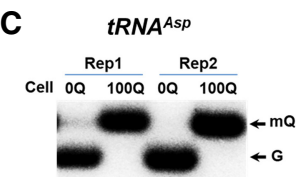

FIGURE 1. Queuosine and glycosylated queuosine modification and acid denaturing gel/northern blot detection. (A) Structure of the protonated queuosine and glycosylated queuosine base. (B) Schematic of acid denaturing gel and northern blot detection of Q- and glycosylated Q-modified tRNAs. Northern blots can be performed using either ${ }^{32} \mathrm{P}$-labeled or 5 ' biotin-labeled tRNA probes. (C) Acid denaturing gel and northern blot showing separation of glycosylated Q-modified tRNA ${ }^{A s p}$ ( $m Q$ : mannosyl-Q) and tRNA ${ }^{\text {Tyr }}$ (gQ: galactosyl-Q) from unmodified tRNA (G) using ${ }^{32} \mathrm{P}$ labeled probes. Asterisk $\left({ }^{*}\right)$ indicates an unknown tRNA ${ }^{\text {Tyr }}$ species. 0Q: total RNA from cells without Q-modification; 100Q: total RNA from cells with full Q-modification. Total RNA was from HEK293T cells. matography (Okada et al. 1977), but this method does not measure the modification fraction. The APB gel method requires only a microgram amount of total RNA, and quantitation is straightforward using northern blots. The principle of APB gel separation is the presence of the cis-diol group on Q-modification that slows the migration of Qmodified versus unmodified tRNA in the presence of APB. This cis-diol group, however, is further modified in the galQ/manQ of tRNA ${ }^{T y r}$ and tRNA ${ }^{\text {Asp }}$, so that the migration of these two tRNAs is no longer distinguishable from unmodified tRNAs in standard APB gels.

Acid denaturing gels are widely used in tRNA charging studies (Varshney et al. 1991). The principle of separating charged versus uncharged tRNA at $\mathrm{pH} \sim 5$ is the protonation of the $\alpha$-amino group of the amino acid attached to the $3^{\prime}$ end of a charged tRNA. Here, we found that the same acid denaturing gel can also separate $Q$ - as well as galQ/manQ-modified tRNAs through the protonation of the secondary amine group (Fig. 1A). After separation, both unmodified and galQ/manQ-modified tRNAs can be quantified by northern blots using ${ }^{32} \mathrm{P}$-labeled as well as nonradioactive, biotinylated DNA probes with similar amounts of input RNA. Our approach therefore uncouples the detection of Q-modification and Q-glycosylation. Using this method, we studied the biological incorporation kinetics of Q- and galQ/manQ-modified tRNAs in three human cell lines. Among the four tRNAs, the rank order of Q-modification rates was tRNA ${ }^{A s p}$, tRNA ${ }^{\text {His }}$, tRNA ${ }^{\text {Tyr }}$, and tRNA ${ }^{\text {Asn, }}$, whereas the glycosylation rates were similar for tRNA ${ }^{A s p}$ and tRNA ${ }^{T y r}$.

\section{RESULTS AND DISCUSSION}

\section{Separation of glycosylated Q-tRNAs by acid denaturing gels}

The current approach of separating Q-modified and unmodified tRNA is based on application of standard denaturing gels supplemented with a boric acid derivative (Igloi and Kossel 1985; Zaborske et al. 2014). This method relies on the cis-diol group in the five membered ring of the Q-base; it does not work for galQ/manQ modifications as the cis-diol is now attached to galactose or mannose. Both $\mathrm{Q}$ and galQ/manO modifications still retain the secondary amine group connecting the modified nucleobase with the five membered ring (Fig. 1A). We reasoned that this amine group may become protonated under $\mathrm{pH} \sim 5$ conditions used to separate aminoacylated from uncharged tRNAs (Varshney et al. 1991). We took advantage of the cell lines generated by us (Wang et al. 2018) that either contains no Q-modification at all (0Q) or 100\% Q-modification (1000) in all tRNAs. After deacylation to remove $3^{\prime}$ attached amino acids, samples were run on $\mathrm{pH}$ 4.8, acid denaturing gels, followed by membrane transfer and northern blot (Fig. 1B). We found that the acid 
denaturing gel can indeed separate gal $\mathrm{Q} / \mathrm{manQ}$-modified from unmodified tRNA ${ }^{\text {Tyr }}$ and tRNA ${ }^{\text {Asp }}$ using ${ }^{32} \mathrm{P}$-labeled tRNA probes (Fig. 1C).

We examined the application of using biotinylated tRNA probes for sensitivity and convenience. After transferring the acid denaturing gel to the membrane, $5^{\prime}$ biotinylated probe was hybridized and then directly detected by streptavidin conjugated horseradish peroxidase (HRP) and Enhanced chemiluminescence (ECL) reagents. We found that our biotin-detection method worked for the glycosylated Q-modified tRNA ${ }^{T y r}$ and tRNA ${ }^{\text {Asp }}$ as well as the Q-modified tRNA ${ }^{\text {His }}$ and tRNA ${ }^{\text {Asn }}$ (Fig. 2A) using a similar amount of total RNA input as ${ }^{32} \mathrm{P}$-labeled tRNA detection. These results demonstrate the practicality of using biotinylated probes in tRNA northern blots with good signal strength and low background.

A prediction of our method is that the acid denaturing gel-based separation of $\mathrm{Q}$, gal $\mathrm{Q} / \mathrm{man} \mathrm{Q}$ and unmodified tRNA should be insensitive to periodate treatment. This is in contrast to APB gel-based separation of $\mathrm{Q}$ and unmodified tRNA, which is eliminated upon periodate oxidation of the cis-diol group on the Q-base (Zaborske et al. 2014). Periodate, however, does not react with the secondary amine group in $\mathrm{Q}$ and $\mathrm{gal} \mathrm{Q} / \mathrm{man} \mathrm{Q}$. Indeed, we found that the separation for tRNA ${ }^{\text {Tyr }}$ and tRNA ${ }^{\text {Asp }}$ was unaffected by periodate treatment (Fig. 2B). As a control, the same periodate reaction eliminated the separation of $\mathrm{Q}$ and unmodified tRNAs in the APB gels (Supplemental Fig. S1). Together, these results validate the utility of acid denaturing gels and biotin-probe northern blots in the analysis of glycosylated Q-modified and also Q-modified tRNAs.

Our periodate and control experiment here used total RNA extracted from $0 \mathrm{O}$ starter cells exposed to queuine after 1 and $24 \mathrm{~h}$. After $24 \mathrm{~h}$ all tRNAs were modified
(Fig. 2B; Supplemental Fig. S1). We noticed in the 1-h time point sample in the APB gel (Supplemental Fig. S1A) that tRNA ${ }^{\text {Tyr }}$ and tRNA ${ }^{\text {Asp }}$ both showed a band sensitive to periodate treatment, suggesting that these were Q-modified tRNA intermediates before they became glycosylated. We took advantage of this result next to measure the tRNA Q-modification kinetics by combining acid denaturing gel and APB gel results.

\section{$\mathrm{Q}$ and galQ/man $\mathrm{Q}$ tRNA modification dynamics in three cell lines}

A biological application of our method is to measure the $\mathrm{Q}$ and glycosylation kinetics in cells to reveal the dynamic nature of these tRNA modifications. Queuine uptake dynamics of its cellular import from extracellular space into the cytosol has been studied previously. A biphasic queuine uptake mechanism was found in which a fast transporter component became saturated within 2-4 min and a slow transporter component equilibrated within 3-4 h (Fergus et al. 2015). Administration of exogenous queuine to tRNA Q-modification depleted germ-free mouse showed faster queuine incorporation for tRNA ${ }^{\text {Asp }}$ than for tRNA ${ }^{\text {His }}$ (Reyniers et al. 1981).

We investigated the Q-modification kinetics in three human cell lines: HEK293T derived from embryonic kidney, HeLa from cervical cancer, and MCF7 from breast cancer. Our experiment started with the $0 \mathrm{O}$ cells we generated as previously described (Wang et al. 2018). At $t=0$, queuine was added at $1 \mu \mathrm{M}$ or $10 \mathrm{nM}$ directly to the medium. The high, $1 \mu \mathrm{M}$ queuine likely results in the saturation of the transport and Q-modification kinetics, while the low, 10 $\mathrm{nM}$ queuine approximates more of the physiological concentration of queuine in body fluids (Katze et al. 1982). The

A
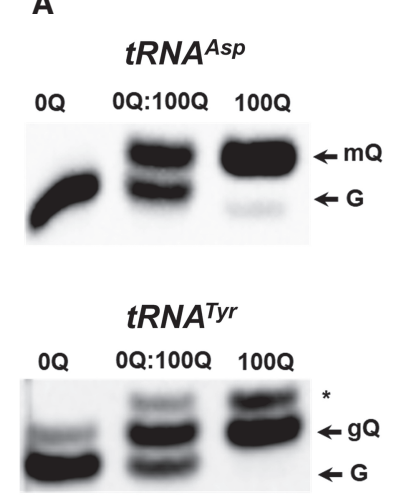

B

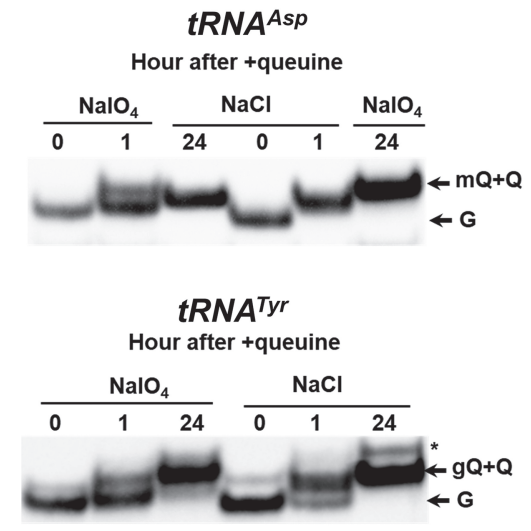

FIGURE 2. Analysis of $\mathrm{Q}$ and glycosylated Q-modified tRNAs using biotinylated tRNA probes. (A) Acid denaturing gels and northern blot of individual, Q or glycosylated Q-modified tRNA. 0Q: total RNA from cells without Q-modification; 100Q: total RNA from cells with full Q-modification; 0Q:100Q: equal amount mixture of $0 \mathrm{Q}$ and $100 \mathrm{Q}$ total RNA. G: unmodified tRNA, Q: Q-modified tRNA, mQ: mannosyl-Q, gQ: galactosyl-Q. (B) Acid denaturing gels and northern blot of $t R N A^{A s p}$ and $t R N A^{\text {Tyr }}$ with $\left(\mathrm{NalO}_{4}\right)$ and without $(\mathrm{NaCl})$ periodate treatment. 0: total RNA from $0 \mathrm{O}$ cells; 1,24 : total RNA from cells 1 and $24 \mathrm{~h}$ after the addition of queuine to $0 \mathrm{O}$ cells. Asterisk $\left(^{*}\right)$ indicates an unknown tRNA ${ }^{T y r}$ species. Total RNA was from MCF7 cells. 
Q-modification kinetics can include the cellular uptake of queuine and its enzymatic incorporation into the cognate tRNAs; both can be affected by the queuine concentrations in the medium.

In HEK293T cells, we found that the total tRNA modification measured by acid denaturing gels occurred at distinct rates for the four cognate tRNAs (Fig. 3). Our result is a combination of multiple steps in the modification pathway which includes a minimum of queuine uptake, a first enzymatic reaction for Q-modification of all four tRNAs, and a second enzymatic reaction for glycosylation of $t R N A^{T y r}$ and tRNA ${ }^{\text {Asp; }}$, none of these steps could be readily measured independently. Instead of trying to fit our result using complex, multistep equations, we chose to use the simplest, one-exponential kinetics fitting of the modification fraction over time to obtain an approximate modification rate and a delay time which may be related to the time lag of queuine uptake. At both high and low queuine concentration, the
A
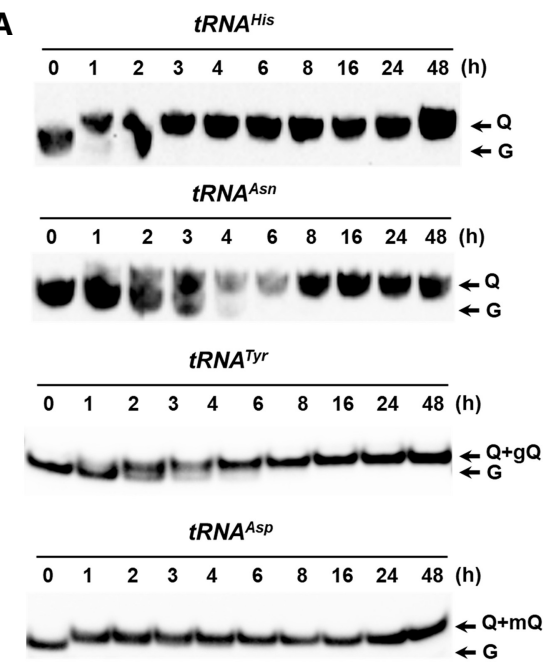

B

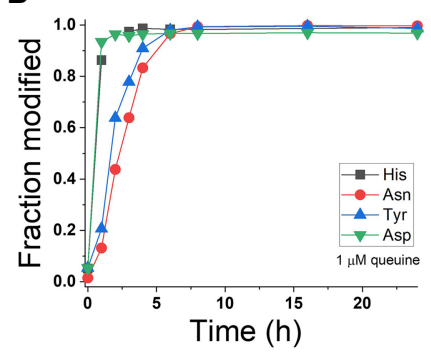

C

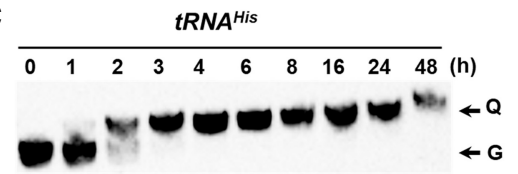

tRNA $A^{A s n}$
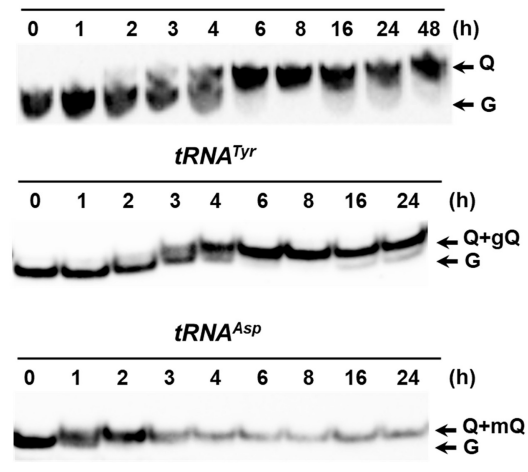

D

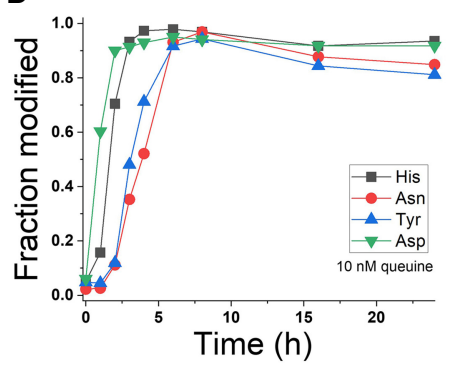

FIGURE 3. $Q$ and glycosylated Q-modification kinetics of HEK293T cells by APB and acid denaturing gels. (A) Time course of individual $\mathrm{Q}$ or glycosylated $\mathrm{Q}$-modified tRNA. At $t=0$, $1 \mu \mathrm{M}$ queuine was added to the medium of $0 \mathrm{Q}$ cells, total RNA was extracted after designated time points in hours. tRNA ${ }^{\text {His }}$ and tRNA ${ }^{\text {Asn }}$ are from APB gels, tRNA ${ }^{\text {Tyr }}$ and tRNA ${ }^{\text {Asp }}$ are from acid denaturing gels. G: unmodified tRNA, Q: Q-modified tRNA, $\mathrm{MQ}$ : mannosyl-Q, gQ: galactosyl-Q. (B) Quantitative modification fraction over time for individual tRNAs, from $1 \mu \mathrm{M}$ queuine data. For tRNA ${ }^{\text {His }}$ and tRNA ${ }^{\text {Asn }}$, the modification fraction represents $Q$; for tRNA ${ }^{\text {Asp }}$ and tRNA ${ }^{T y r}$, the modification fraction represents the sum of the $Q$ and glycosylated $Q$ modifications. $(C, D)$ Same as $A, B$ except at $t=0,10 \mathrm{nM}$ queuine was added to the medium of 00 cells. rank order of modification rate was tRNA ${ }^{\text {Asp }}>t_{R N A} A^{\text {His }}>$ tRNA $^{\mathrm{Tyr}} \sim \mathrm{tRNA}^{\text {Asn }}$, with $\mathrm{tRNA}^{\mathrm{Asp}}$ modified the fastest (Table 1). The rate difference between the fastest and the slowest tRNA was $\sim 10$-fold at high and approximately fourtial decayfitwe found the glycosylation ratesto be aboutt same at high and low queuine concentration for both tRNA $^{\text {Asp }}$ and tRNA ${ }^{\text {Tyr }}$. Compared to the Q-modification rate, the glycosylation rate was more than approximately threefold slower for tRNA ${ }^{\text {Asp }}$ but was about the same for tRNA ${ }^{T y r}$, thus explaining the appearance of the relatively high levels of Q-modified tRNA ${ }^{\text {Asp }}$ intermediate.

We also determined the Q-modification kinetics in HeLa and MCF7 cells using the same combination of acid denaturing gels and APB gels (Table 1; Supplemental Figs. S2-S5). In these cells, the rank order of tRNA ${ }^{\text {Asp }}>$ tRNA ${ }^{\text {His }}>$ tRNA $^{\text {Tyr }} \sim$ tRNA $^{\text {Asn }}$ was maintained, although the absolute rate constant was variable. The delay time was also of a similar magnitude as those in HEK293T cells. Still, even the lowest modification rate (tRNA ${ }^{\text {Asn }}$ ) in all cases was $0.25 \mathrm{~h}^{-1}$, corresponding to a half-life of modification of $\sim 3 \mathrm{~h}$. The glycosylation rates for HeLa and MCF7 were up to 2.5 times faster than for HEK293T which may reflect the expression differences of the unknown glycosylase enzymes in these cells.

\section{Concluding remarks}

In summary, we developed an acid denaturing gel method for the detection and quantitation of glycosylated Q-modified tRNAs. Our method takes advantage of the protonation of an amine group in the modified base; in principle it should also be applicable for other human tRNA modifications such as N3-(3-amino-3-carboxypropyl)-uridine $\left(\operatorname{acp}^{3} \mathrm{U}\right.$ ) (Chen and Roe 1980). Our acid denaturing gel method requires only microgram amounts of total RNA and setups in every laboratory. The acid denaturing 
TABLE 1. $\mathrm{Q}$ and glycosylated $\mathrm{Q}$ modification rates in three human cell lines

\begin{tabular}{|c|c|c|c|c|c|c|c|c|}
\hline \multirow[b]{2}{*}{ Queuine } & \multicolumn{2}{|c|}{ Asp } & \multicolumn{2}{|c|}{ His } & \multicolumn{2}{|c|}{ Tyr } & \multicolumn{2}{|c|}{ Asn } \\
\hline & Rate $\left(h^{-1}\right)^{f}$ & Delay (h) & Rate $\left(h^{-1}\right)^{f}$ & Delay (h) & Rate $\left(\mathrm{h}^{-1}\right)$ & Delay (h) & Rate $\left(\mathrm{h}^{-1}\right)$ & Delay (h) \\
\hline \multicolumn{9}{|l|}{ HEK293Т } \\
\hline $1 \mu \mathrm{M}$ & $\begin{array}{l}3.4 \pm 0.2^{a} \\
0.41 \pm 0.02^{b}\end{array}$ & 0 & $2.1 \pm 0.2^{c}$ & 0 & $\begin{array}{l}0.46 \pm 0.07^{d} \\
0.35 \pm 0.03^{e}\end{array}$ & 0.03 & $0.35 \pm 0.05^{c}$ & 0.2 \\
\hline $10 \mathrm{nM}$ & $\begin{array}{l}1.1 \pm 0.1^{\mathrm{a}} \\
0.41 \pm 0.06^{\mathrm{b}}\end{array}$ & 0 & $0.59 \pm 0.14^{c}$ & 0.05 & $\begin{array}{l}0.31 \pm 0.10^{d} \\
0.35 \pm 0.03^{e}\end{array}$ & 0.35 & $0.25 \pm 0.08^{c}$ & 0.5 \\
\hline \multicolumn{9}{|l|}{ HeLa } \\
\hline $1 \mu \mathrm{M}$ & $\begin{array}{l}1.6 \pm 0.3^{a} \\
0.43 \pm 0.07^{b}\end{array}$ & 0 & $1.5 \pm 0.2^{c}$ & 0 & $\begin{array}{l}0.65 \pm 0.09^{d} \\
0.49 \pm 0.10^{e}\end{array}$ & 0 & $0.51 \pm 0.16^{c}$ & 0.2 \\
\hline $10 \mathrm{nM}$ & $\begin{array}{l}0.86 \pm 0.16^{a} \\
0.65 \pm 0.08^{b}\end{array}$ & 0.07 & $0.55 \pm 0.19^{c}$ & 0.2 & $\begin{array}{l}0.23 \pm 0.05^{d} \\
0.61 \pm 0.02^{e}\end{array}$ & 0.2 & $0.25 \pm 0.11^{c}$ & 0.6 \\
\hline \multicolumn{9}{|l|}{ MCF7 } \\
\hline $1 \mu \mathrm{M}$ & $\begin{array}{l}5.3 \pm 0.8^{a} \\
0.87 \pm 0.08^{b}\end{array}$ & 0 & $1.3 \pm 0.2^{c}$ & 0.04 & $\begin{array}{l}0.86 \pm 0.19^{d} \\
0.42 \pm 0.04^{e}\end{array}$ & 0.04 & $0.59 \pm 0.09^{c}$ & 0.06 \\
\hline $10 \mathrm{nM}$ & $\begin{array}{l}1.2 \pm 0.1^{\mathrm{a}} \\
0.49 \pm 0.12^{\mathrm{b}}\end{array}$ & 0 & $0.50 \pm 0.10^{c}$ & 0.14 & $\begin{array}{l}0.35 \pm 0.08^{d} \\
0.91 \pm 0.08^{e}\end{array}$ & 0.25 & $0.34 \pm 0.16^{c}$ & 0.25 \\
\hline $\begin{aligned} &{ }^{\mathrm{a}} \mathrm{G} \rightarrow \mathrm{Q}+\mathrm{m} \\
&{ }^{\mathrm{b}} \mathrm{Q} \rightarrow \mathrm{man} \mathrm{C} \\
&{ }^{\mathrm{c}} \mathrm{G} \rightarrow \mathrm{Q} . \\
&{ }^{\mathrm{d}} \mathrm{G} \rightarrow \mathrm{Q}+\mathrm{g} \\
&{ }^{\mathrm{e}} \mathrm{Q} \rightarrow \text { gal } \mathrm{Q} \\
&{ }^{\mathrm{f}} \text { Errors are }\end{aligned}$ & urve fitting & & & & & & & \\
\hline
\end{tabular}
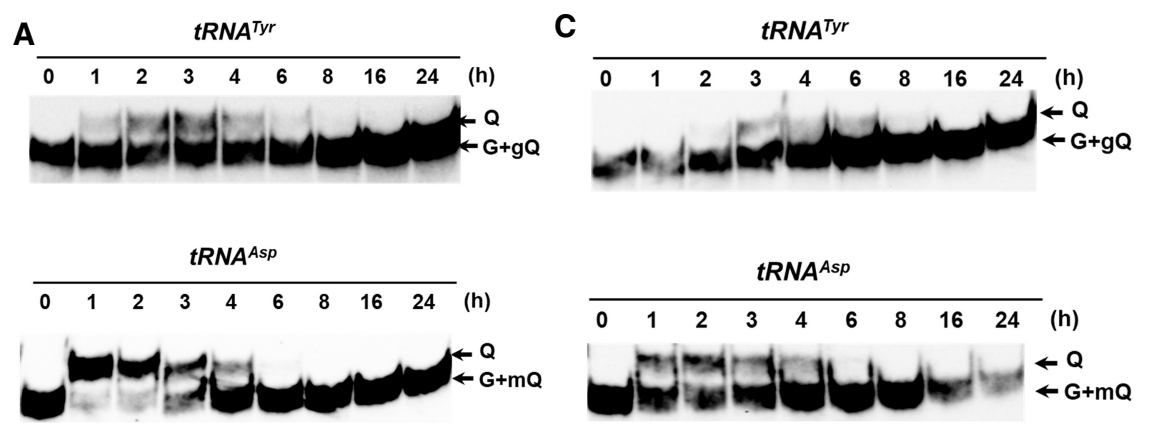

B

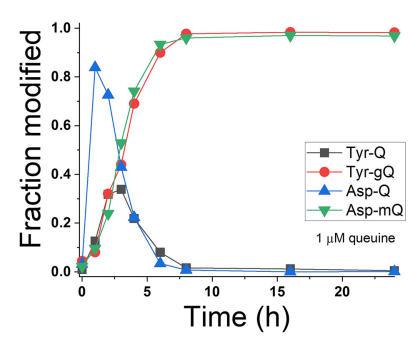

D

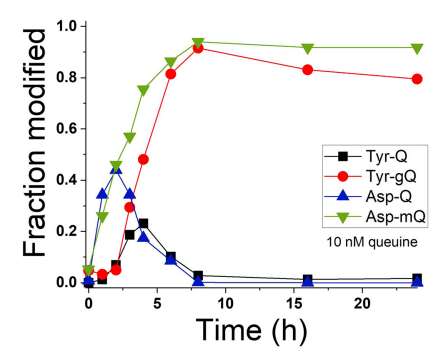

FIGURE 4. Q-modification kinetics of tRNA ${ }^{\text {Asp }}$ and tRNA ${ }^{\text {Tyr }}$ in HEK293T cells by APB gels. (A) At $t=0,1 \mu \mathrm{M}$ queuine was added to the medium of $0 \mathrm{Q}$ cells, total RNA was extracted after designated time points in hours. G: unmodified tRNA, Q: Q-modified tRNA, mQ: mannosyl-Q, $\mathrm{gQ}$ : galactosyl-Q. The reversal to fast migration in later time points corresponds to $\mathrm{gQ}$ or $\mathrm{mQ}$ products as indicated by the acid denaturing gel results from Figure 3. (B) Quantitative modification fraction over time for individual tRNAs, from $1 \mu \mathrm{M}$ queuine data. For comparison the total modification fraction from acid denaturing gel results in Figure 3 are also shown. $(C, D)$ Same as $A, B$ except at $t=0,10 \mathrm{nM}$ queuine was added to the medium of 00 cells. gel method relies on the charge difference between unmodified and modified tRNAs, so a limitation of the method is the difficulty of separating Q-modified from glycosylated Q-modified tRNAs. APB gel relies on the chemistry of the cis-diol and boric acid derivatives in the gel, so a limitation of the method is the difficulty of separating unmodified from glycosylated Q-modified tRNAs. By combining acid denaturing gel and the previously established APB gel for Q-modified tRNAs, our method allows for comprehensive analysis of $\mathrm{Q}$ and glycosylated Q-modifications in all human tRNAs.

Quantification of tRNA modification fractions is a crucial aspect of functional analysis of RNA modification. Our method is of interest specifically for the studies of glycosylated Q-modified tRNAs which had been difficult to perform due to the difficulties and limitations of existing approaches. Furthermore, the ease of northern blots using biotinylated tRNA probes should enable more 
widespread applications of the acid denaturing gel and the APB gel methods described here. Future studies will include the identification of the glycosylation enzymes (Okada and Nishimura 1977) and the functional analysis of these tRNA glycosylation modifications with yet-to-be assigned biological functions.

\section{MATERIALS AND METHODS}

\section{Generation of 00 and 1000 cells}

HEK293T, HeLa, and MCF7 cells were cultured with complete DMEM or EMEM medium under standard conditions. The 00 and 1000 cells were obtained as previously described (Wang et al. 2018). Briefly, MCF7 cells were grown in EMEM medium (ATCC, 30-2003) with dialyzed 10\% FBS (Thermo Fisher Scientific 26400044), $0.01 \mathrm{mg} / \mathrm{mL}$ bovine insulin (Sigma-Aldrich I0516), and $10 \mathrm{nM} \beta$-estradiol (Sigma-Aldrich E2758) to $80 \%$ confluency and passaged. HEK293T and HeLa cells were grown in Hyclone DMEM medium (GE Healthcare Life Sciences SH30022.01) with $10 \%$ dialyzed FBS to $80 \%$ confluency and passaged. Total RNAs were extracted using TRIzol (Thermo Fisher Scientific 15596026) by following the manufacturer's manual at each passage and the Q-modification fraction of the tRNA ${ }^{\mathrm{His} / \mathrm{Asn}}$ was determined using APB gel and northern blot. After $\sim 10$ passages, $\mathrm{Q}$ was depleted from these three cell lines (0Q cells). To get 1000 cells (100\% Q-modified), 00 cells were grown to $60 \%-80 \%$ confluency and queuine was added to the medium to $1 \mu \mathrm{M}$ final concentration. The cells were cultured for an additional $24 \mathrm{~h}$ to become fully Q-modified.

\section{Acid denaturing gel electrophoresis and northern blot}

Three $\mu \mathrm{g}$ total RNA of each sample was added to a microcentrifuge tube in $4.5 \mu \mathrm{L} \mathrm{H}_{2} \mathrm{O}$. $0.5 \mu \mathrm{L} 1 \mathrm{M}$ Tris- $\mathrm{HCl}$ ( $\mathrm{pH}$ 9.0) was added to each tube and mixed. The tubes were incubated at $37^{\circ} \mathrm{C}$ for 30 min to deacylate tRNAs. The tubes were briefly centrifuged and 5 $\mu \mathrm{L} 2 \times$ acidic RNA loading dye (8 M Urea, 0.1 M HOAc/NaOAc, pH $4.8,0.05 \%$ Bromophenol blue, $0.05 \%$ Xylene cyanol) were added to each tube. All samples ( $10 \mu \mathrm{L}$ each) were loaded to a $12 \%$ prerun $0.4 \mathrm{~mm}$ thick acid denaturing PAGE gel $(1 \times \mathrm{TBE}, 0.1 \mathrm{M}$ $\mathrm{NaOAc} / \mathrm{HOAc}, \mathrm{pH} 4.8)$. The gel was run at $16 \mathrm{~W}$ for $8 \sim 9 \mathrm{~h}$ in $4^{\circ} \mathrm{C}$ cold room with acid TAE running buffer $(1 \times \mathrm{TAE}, 0.1 \mathrm{M} \mathrm{NaOAc} /$ $\mathrm{HOAc}, \mathrm{pH}$ 4.8) until the xylene cyanol band was near the bottom. The gel area with the target RNA was cut and Hybond-XL membrane was put on top of the gel to take the gel out of the plate. The gel area with the target RNA was then transferred to Hybond-XL membrane (GE Healthcare, RPN303S) under a vacuum using a gel dryer (Bio-Rad, 1651745) for $4 \mathrm{~h}$ at $80^{\circ} \mathrm{C}$. The gel was removed from the membrane by soaking the gel and membrane in distilled water. The membrane was UV-crosslinked two times (254 nm, $1200 \mathrm{~mJ}$ ) and blocked for 30 minutes twice with hybridization buffer (20 mM phosphate, $\mathrm{pH} 7,300 \mathrm{mM} \mathrm{NaCl}, 1 \%$ SDS). The membrane was incubated with $3 \mathrm{pmol} / \mathrm{ml}$ biotinylated tRNA probes for $16 \mathrm{~h}$ at $60^{\circ} \mathrm{C}$ in the UVP Hybridizer Oven (Analytik Jena 95-0030-01). The membrane was washed for 30 min twice with $50 \mathrm{~mL}$ washing buffer (20 mM phosphate, $\mathrm{pH} 7$,
$300 \mathrm{mM} \mathrm{NaCl}, 2 \mathrm{mM}$ EDTA, and 0.1\% SDS). The membrane was then incubated with streptavidin-HRP conjugate (Genscript M00091) in $30 \mathrm{~mL}$ hybridization buffer (1:5000-1:10,000 dilution) for $30 \mathrm{~min}$ at room temperature. The membrane was washed three times for 5 min each in $25 \mathrm{~mL}$ washing buffer. The membrane was transferred to plastic wrap with the RNA-side facing up. Peroxidase detection reagent 1 and 2 (Bio-Rad 1705061) were mixed $\left(0.1 \mathrm{~mL}\right.$ per $1 \mathrm{~cm}^{2}$ membrane) and applied to the top of the membrane by pipetting. The membrane was incubated with the reagent mixture for $5 \mathrm{~min}$. The membrane was transferred to a new plastic wrap. The membrane was scanned using ChemiDoc imaging system (Bio-Rad) and the data was analyzed using ImageLab.

The oligonucleotide probe sequences were: tRNA ${ }^{\text {His }}$ : 5'-biotin-TGCCGTGACTCGGATTCGAACCGAGGTTGCTGCGGCCACAACGCAGAGTACTAACCACTATACGATCACGGC; tRNA ${ }^{\text {Asn: }}$ 5'-biotin-CGTCCCTGGGTGGGCTCGAACCACCAACCTTTCGG TTAACAGCCGAACGCGCTAACCGATTGCGCCACAGAGAC; tRNA ${ }^{\text {Asp: }}$ 5'-biotin-CTCCCCGTCGGGGAATCGAACCCCGGTC TCCCGCGTGACAGGCGGGGATACTCACCACTATACTAACGA GGA; tRNA ${ }^{\text {Tyr }}$ : 5'-biotin-TCCTTCGAGCCGGASTCGAACCAGC GACCTAAGGATCTACAGTCCTCCGCTCTACCARCTGAGCTAT CGAAGG.

\section{APB gel electrophoresis}

Three $\mu \mathrm{g}$ total RNA of each sample was deacylated with $5 \mu \mathrm{L} 0.1 \mathrm{M}$ Tris- $\mathrm{HCl}(\mathrm{pH} 9.0)$ at $37^{\circ} \mathrm{C}$ for $30 \mathrm{~min}$. An amount of $5 \mu \mathrm{L} 2 \times \mathrm{RNA}$ loading dye (8 M Urea, 0.05\% Bromophenol blue, 0.05\% Xylene cyanol) was added to each tube after centrifugation. $10 \%$ denaturing PAGE gel with $0.5 \%(\mathrm{~g} / \mathrm{mL})$ Acrylamidophenylboronic acid (APB) was prepared and prerun at $18 \mathrm{~W}$ for $30 \mathrm{~min}$ in the $4^{\circ} \mathrm{C}$ cold room using $1 \times$ TAE buffer. All samples were loaded onto the $10 \%$ denaturing PAGE gel with APB and the gel was run at $18 \mathrm{~W}$ for $\sim 2-3 \mathrm{~h}$ until the xylene cyanol band was near the bottom. The gel was transferred and blotted as described above.

\section{Periodate reaction}

Six micrograms of HEK293T total RNA treated with $1 \mu \mathrm{M}$ queuine for 0,1 , and $24 \mathrm{~h}$ were deacylated in $20 \mu \mathrm{L} \mathrm{0.1} \mathrm{M} \mathrm{Tris-} \mathrm{HCl}$ (pH 9.0) at $37^{\circ} \mathrm{C}$ for $30 \mathrm{~min}$. The RNA was concentrated using Zymo RNA clean and concentrator-5 kit (Zymo R1016) and eluted in $6 \mu \mathrm{L}$ sterile $\mathrm{H}_{2} \mathrm{O}$. The eluted RNA was split into two tubes ( $3 \mu \mathrm{L}$ each). $5 \times$ periodate mix $(250 \mathrm{mM}$ ) was made by dissolving $27 \mathrm{mg}$ sodium periodate in $417 \mu \mathrm{L} \mathrm{H} \mathrm{H}_{2} \mathrm{O}$ and $83 \mu \mathrm{L}$ of $3 \mathrm{M}$ sodium acetate $(\mathrm{pH}$ 4.8). $0.75 \mu \mathrm{L} 5 \times$ periodate mix was added to each tube and the tubes were incubated at room temperature for $30 \mathrm{~min}$. The reaction was quenched with $0.75 \mu \mathrm{L}$ of $1 \mathrm{M}$ ribose for $5 \mathrm{~min}$ at room temperature. $4.5 \mu \mathrm{L} 2 \times$ acidic RNA loading dye was added to each tube and all samples were loaded onto a $12 \%$ prerun acid denaturing PAGE gel. The gel was transferred and blotted as described above.

\section{Time course study}

HEK293T, MCF7, and HeLa cells were cultured in a six-well plate as described above to $60 \%-80 \%$ confluency. An amount of $1 \mathrm{mM}$ 
or $10 \mu \mathrm{M}$ queuine stock solution in water was added to the medium to get a $1 \mu \mathrm{M}$ or $10 \mathrm{nM}$ final queuine concentration at $t=0$. At designated time points, the medium was removed and cells were washed by PBS twice. Total RNA was extracted immediately by adding $0.5 \mathrm{~mL}$ TRIzol reagent to each well and following the manufacturer's manual. The modification status of $Q$ and glycosylated Q-modified tRNAs (His, Asn, Tyr, Asp) at different time points and different queuine concentrations were examined by APB or acid denaturing PAGE gel as described above.

Clearly, multiple processes are involved in installing $\mathrm{Q}$ and manQ/galQ modifications over time including at least the queuine uptake, Q-modification by the QTRT1 enzyme, and glycosylation by another, unknown enzyme. Instead of fitting the time courses using the consideration of all these parameters, we choose to use the simplest curve fitting equations with a simple goal to obtain plausible kinetic parameters.

The time courses for total $\mathrm{Q}$ and $\mathrm{Q}+$ man $\mathrm{Q} / \mathrm{gal} \mathrm{Q}$ modification (Fig. 3) were fit to a single exponential growth: $y=A\left(1-e^{-k(t-t 0)}\right)$, where $k$ is the rate constant of total tRNA modification, t0 is the delay time, and $A$ is the maximal modification fraction. For $1 \mu \mathrm{M}$ and $10 \mathrm{nM}$ queuine data, the fit coefficients for HEK293T ranged from $r^{2}=0.964-0.999$ and 0.886-0.991, for HeLa from $r^{2}=0.898-$ 0.976 and $0.839-0.955$, and for MCF7 from $r^{2}=0.930-0.995$ and $0.950-0.984$, respectively.

The time courses for Q-to-manQ/galQ (Fig. 4) starting with the time point with the highest fraction (B) of accumulated $\mathrm{Q}$-modified tRNA were fit to a single exponential decay $y=B\left(e^{-k t}\right)$, where $k$ is the rate constant of Q-to-manQ/galQ conversion. For both 1 $\mu \mathrm{M}$ and $10 \mathrm{nM}$ queuine data, the fit coefficients for HEK293T ranged from $r^{2}=0.987-0.997$, for HeLa from $r^{2}=0.987-0.999$, and for MCF7 from $r^{2}=0.982-0.999$.

\section{SUPPLEMENTAL MATERIAL}

Supplemental material is available for this article.

\section{ACKNOWLEDGMENTS}

This work was supported by the Department of Defense/ Congressionally Directed Medical Research Programs (DoD/ CDMRP) (BC160450 to T.P.), the National Institute of General Medical Sciences (NIGMS) (R01GM113194 to T.P.), and the China Scholarship Council (grant number: 201906320410 to R.X.).

Received March 27, 2020; accepted May 19, 2020.

\section{REFERENCES}

Bednarova A, Hanna M, Durham I, VanCleave T, England A, Chaudhuri A, Krishnan N. 2017. Lost in translation: defects in transfer RNA modifications and neurological disorders. Front Mol Neurosci 10: 135. doi:10.3389/fnmol.2017.00135

Chen EY, Roe BA. 1980. Structural comparison of human, bovine, rat, and Walker 256 carcinosarcoma asparaginyl-tRNA. Biochim Biophys Acta 610: 272-284. doi:10.1016/0005-2787(80)90009-X

Costa A, de Barros JP P, Keith G, Baranowski W, Desgres J. 2004. Determination of queuosine derivatives by reverse-phase liquid chromatography for the hypomodification study of Q-bearing tRNAs from various mammal liver cells. J Chromatogr B Analyt
Technol Biomed Life Sci 801: 237-247. doi:10.1016/j.jchromb .2003.11.022

Ehrenhofer-Murray AE. 2017. Cross-talk between Dnmt2-dependent tRNA methylation and queuosine modification. Biomolecules 7: 14. doi:10.3390/biom7010014

Fergus C, Barnes D, Alqasem MA, Kelly VP. 2015. The queuine micronutrient: charting a course from microbe to man. Nutrients 7: 2897-2929. doi:10.3390/nu7042897

Igloi GL, Kossel H. 1985. Affinity electrophoresis for monitoring terminal phosphorylation and the presence of queuosine in RNA. Application of polyacrylamide containing a covalently bound boronic acid. Nucleic Acids Res 13: 6881-6898. doi:10.1093/nar/13 .19 .6881

Kasai H, Kuchino Y, Nihei K, Nishimura S. 1975. Distribution of the modified nucleoside $\mathrm{Q}$ and its derivatives in animal and plant transfer RNA's. Nucleic Acids Res 2: 1931-1939. doi:10.1093/ nar/2.10.1931

Kasai H, Nakanishi K, Macfarlane RD, Torgerson DF, Ohashi Z, McCloskey JA, Gross HJ, Nishimura S. 1976. Letter: the structure

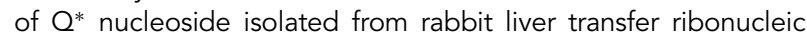
acid. J Am Chem Soc 98: 5044-5046. doi:10.1021/ja00432a071

Katze JR, Basile B, McCloskey JA. 1982. Queuine, a modified base incorporated posttranscriptionally into eukaryotic transfer RNA: wide distribution in nature. Science 216: $55-56$. doi:10.1126/sci ence.7063869

Machnicka MA, Milanowska K, Osman Oglou O, Purta E, Kurkowska M, Olchowik A, Januszewski W, Kalinowski S, DuninHorkawicz S, Rother KM, et al. 2013. MODOMICS: a database of RNA modification pathways-2013 update. Nucleic Acids Res 41: D262-D267. doi:10.1093/nar/gks1007

Meier F, Suter B, Grosjean H, Keith G, Kubli E. 1985. Queuosine modification of the wobble base in tRNA ${ }^{\text {His }}$ influences 'in vivo' decoding properties. EMBO J 4: 823-827. doi:10.1002/j.1460-2075 .1985.tb03704.x

Müller M, Legrand C, Tuorto F, Kelly VP, Atlasi Y, Lyko F, EhrenhoferMurray AE. 2019. Queuine links translational control in eukaryotes to a micronutrient from bacteria. Nucleic Acids Res 47: 37113727. doi:10.1093/nar/gkz063

Okada N, Nishimura S. 1977. Enzymatic synthesis of Q* nucleoside containing mannose in the anticodon of tRNA: isolation of a novel mannosyltransferase from a cell-free extract of rat liver. Nucleic Acids Res 4: 2931-2938. doi:10.1093/nar/4.8.2931

Okada N, Shindo-Okada N, Nishimura S. 1977. Isolation of mammalian tRNA ${ }^{\text {Asp }}$ and tRNA ${ }^{\text {Tyr }}$ by lectin-Sepharose affinity column chromatography. Nucleic Acids Res 4: 415-423. doi:10.1093/nar/4.2 .415

Pan T. 2018. Modifications and functional genomics of human transfer RNA. Cell Res 28: 395-404. doi:10.1038/s41422-0180013-y

Pathak C, Jaiswal YK, Vinayak M. 2008. Queuine promotes antioxidant defence system by activating cellular antioxidant enzyme activities in cancer. Biosci Rep 28: 73-81. doi:10.1042/ BSR20070011

Reyniers JP, Pleasants JR, Wostmann BS, Katze JR, Farkas WR. 1981. Administration of exogenous queuine is essential for the biosynthesis of the queuosine-containing transfer RNAs in the mouse. $J$ Biol Chem 256: 11591-11594.

Tuorto F, Legrand C, Cirzi C, Federico G, Liebers R, Müller M, Ehrenhofer-Murray AE, Dittmar G, Grone HJ, Lyko F. 2018. Queuosine-modified tRNAs confer nutritional control of protein translation. EMBO J 37: e99777. doi:10.15252/embj .201899777

Varshney U, Lee CP, RajBhandary UL. 1991. Direct analysis of aminoacylation levels of tRNAs in vivo. Application to studying 


\section{Zhang et al.}

recognition of Escherichia coli initiator tRNA mutants by glutaminyl-tRNA synthetase. J Biol Chem 266: 24712-24718.

Vinayak M, Pathak C. 2009. Queuosine modification of tRNA: its divergent role in cellular machinery. Biosci Rep 30: 135-148. doi:10 .1042/BSR20090057

Wang X, Matuszek Z, Huang Y, Parisien M, Dai Q, Clark W, Schwartz MH, Pan T. 2018. Queuosine modification protects cog- nate tRNAs against ribonuclease cleavage. RNA 24: 1305-1313. doi:10.1261/rna.067033.118

Zaborske JM, DuMont VL, Wallace EW, Pan T, Aquadro CF, Drummond DA. 2014. A nutrient-driven tRNA modification alters translational fidelity and genome-wide protein coding across an animal genus. PLoS Biol 12: e1002015. doi:10.1371/journal.pbio .1002015 

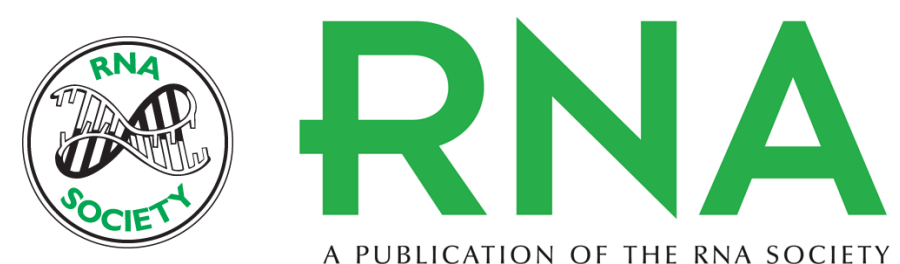

A PUBLICATION OF THE RNA SOCIETY

\section{Detection and quantification of glycosylated queuosine modified tRNAs by acid denaturing and APB gels}

Wen Zhang, Ruyi Xu, Zaneta Matuszek, et al.

RNA 2020 26: 1291-1298 originally published online May 21, 2020

Access the most recent version at doi:10.1261/rna.075556.120

\section{Supplemental http://rnajournal.cshlp.org/content/suppl/2020/05/21/rna.075556.120.DC1 \\ Material}

References This article cites 22 articles, 5 of which can be accessed free at: http://rnajournal.cshlp.org/content/26/9/1291.full.html\#ref-list-1

Creative This article is distributed exclusively by the RNA Society for the first 12 months after the Commons

License full-issue publication date (see http://rnajournal.cshlp.org/site/misc/terms.xhtml). After 12 months, it is available under a Creative Commons License (Attribution-NonCommercial 4.0 International), as described at http://creativecommons.org/licenses/by-nc/4.0/.

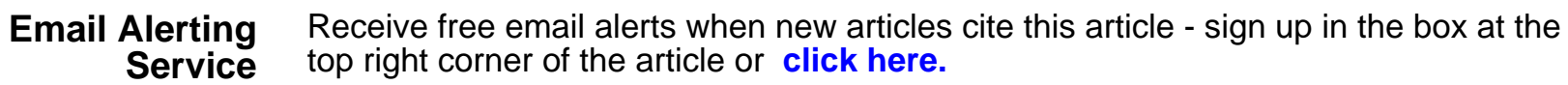

